\title{
A case report of achondrogenesis type II (Langer-Saldino achondrogenesis)
}

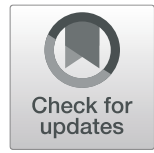

\author{
Saurabh Maheshwari ${ }^{*}$, Dilip Ingole, Samar Chatterjee, Uddandam Rajesh and Varun Anand
}

\begin{abstract}
Background: Achondrogenesis type II is a rare autosomal dominant skeletal dysplasia with a frequency of $\sim 0.2$ per 100,000 births. It is one of the lethal short-limbed dwarfisms associated with structural mutations in type II collagen and is also known as Langer-Saldino achondrogenesis. It is characterized by severe micromelia (shortening of entire limb), narrow chest, and prominent abdomen. It shares the striking feature of partial or complete vertebral body demineralization with achondrogenesis type I.

Case presentation: We present a case with antenatal diagnosis of this rare entity which was confirmed by posttermination radiographs of abortus.

Conclusion: The imaging plays a cardinal role in the diagnosis of this condition. This case represents only the 4th case of this rare entity from India.
\end{abstract}

Keywords: Achondrogenesis type 2, Langer-Saldino achondrogenesis, Prenatal ultrasonography, Collagen type II, Fetal imaging

\section{Background}

Achondrogenesis type II is a rare autosomal dominant skeletal dysplasia with a frequency of $\sim 0.2$ per 100,000 births [1]. It is one of the lethal short-limbed dwarfisms associated with structural mutations in type II collagen and is also known as Langer-Saldino achondrogenesis [2]. It is due to a mutation in the collagen, type II, alpha 1 (COL2A1) gene on chromosome 12. Achondrogenesis type II usually arises due to a de novo mutation. However, there have been two case reports of germline mosaicism leading to recurrence of this condition in a subsequent pregnancy $[3,4]$.

\section{Case presentation}

A 26-year-old primigravida reported for the routine mid-trimester scan at a period of gestation of 18 weeks 5 days. The pregnancy was the product of a nonconsanguineous marriage. Earlier, she had undergone a pregnancy confirmation scan at 6 weeks period of

\footnotetext{
* Correspondence: saurabhmhshwr@yahoo.co.in

Department of Radiodiagnosis and Imaging, Armed Forces Medical College, Pune, India
}

\section{Springer Open}

(ㄷ) The Author(s). 2021 Open Access This article is licensed under a Creative Commons Attribution 4.0 International License, which permits use, sharing, adaptation, distribution and reproduction in any medium or format, as long as you give appropriate credit to the original author(s) and the source, provide a link to the Creative Commons licence, and indicate if changes were made. The images or other third party material in this article are included in the article's Creative Commons licence, unless indicated otherwise in a credit line to the material. If material is not included in the article's Creative Commons licence and your intended use is not permitted by statutory regulation or exceeds the permitted use, you will need to obtain permission directly from the copyright holder. To view a copy of this licence, visit http://creativecommons.org/licenses/by/4.0/. mester scan for the assessment of markers of fetal aneuploidy. Her pregnancy was uneventful until then with no history of hypertension or raised blood sugar levels. Her family history was unremarkable. The second trimester clinical examination before the ultrasound did not reveal any abnormality.

The patient reported to the department of radiodiagnosis at our tertiary care center in Southern India for this scan as per hospital protocol. The ultrasound examination revealed multiple fetal abnormalities. It was a singleton pregnancy showing extreme micromelia with femur length (Hadlock) and humeral length (Jeanty) both corresponding to 13 weeks 4 days (Fig. 1). The ratio of femoral length and abdominal circumference (FL/AC ratio) was 0.08 (normal range 0.20-0.25), which indicated a lethal skeletal dysplasia [5]. The most remarkable finding was almost complete non-visualization of vertebral body ossification centers (Fig. 2) with only two echogenic posterior elements seen in the transverse image of the fetal spine. Also, there was a gross increase in nuchal fold thickness which measured $\sim 11.6 \mathrm{~mm}$ (Fig. 3). There was relative 


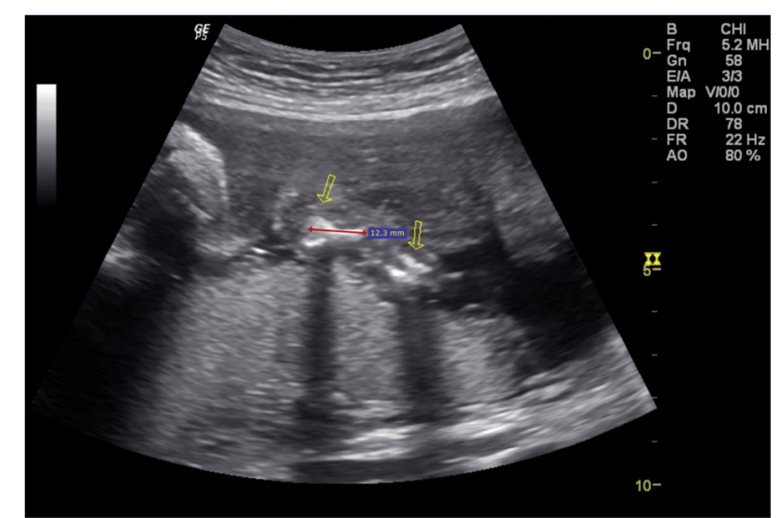

Fig. 1 Ultrasound image of the right lower limb of the fetus in a longitudinal plane shows severe micromelia with shortening of the femur, tibia, and fibula (arrows). The femoral length corresponds to 13 weeks 4 days period of gestation

macrocrania with normal-appearing ossification on ultrasound. There were no obvious brain abnormalities. The skull and ribs showed normal ossification. There was no evidence of neural tube defect, rib fractures, rib length discrepancy, or hydrops. The volume of liquor was normal.

Based on these findings, suspicion of type II collagen disorder was raised, and the patient was counseled about the poor prognosis. The patient opted for termination of pregnancy as Indian law allows termination of pregnancy up to 20 weeks for fetal abnormalities. The abortus (Fig. 4) showed marked micromelia, relatively large head, narrow thorax, and distended abdomen. Bilateral clubfeet were noted. No cleft lip or polydactyly was seen.

The postnatal radiographs of the abortus revealed severely short fetal long bones, complete non-ossification of vertebral bodies (including sacrum), relative macrocrania, narrow thorax, shortening of the trunk, cupped

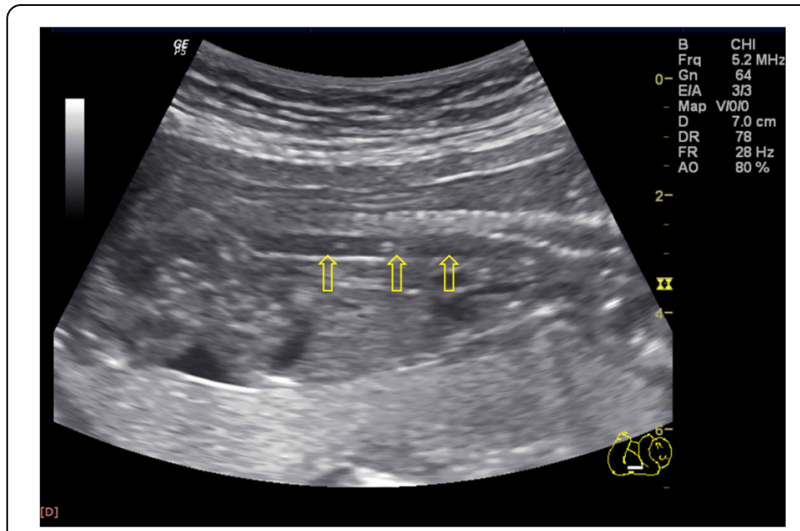

Fig. 2 Midsagittal ultrasound image of the fetus shows the nearcomplete absence of vertebral body ossification centers in the entire extent of the spine (arrows)

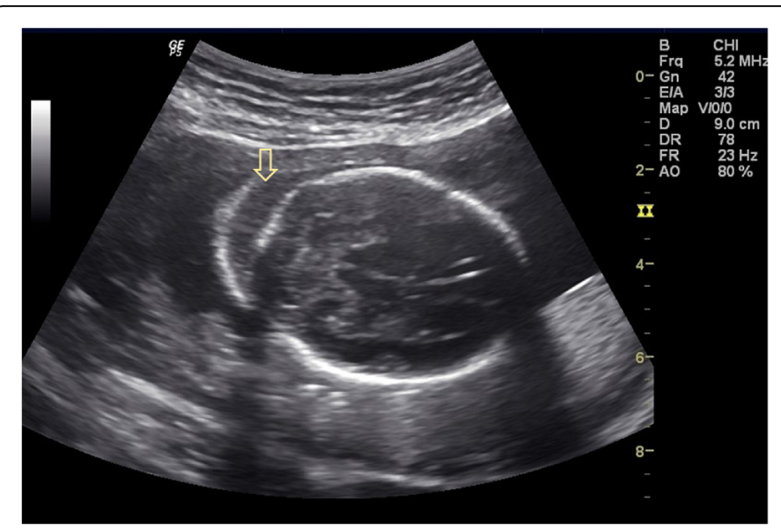

Fig. 3 Axial image of the fetal head at the level of cerebellum shows grossly increased nuchal fold thickness (arrow)

appearance of ribs without any fractures, and concavity of inferior and medial borders of ilium which has also been described as "paraglider appearance" [6] (Fig. 5). The ossification centers of ischium and pubis were also not visualized. The metaphyses of long bones appeared flared with lateral spurs seen at proximal metaphyses of bilateral humeri and femora. The skull appeared normal in size and mineralization.

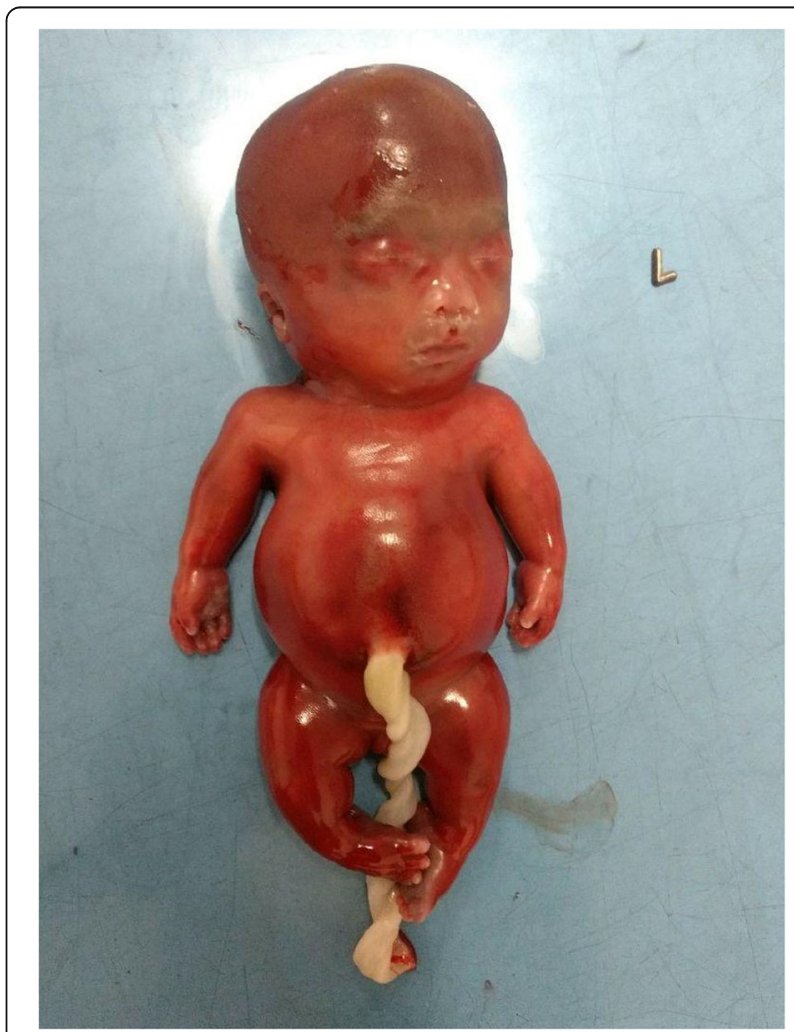

Fig. 4 Post-termination photograph of the abortus shows marked micromelia, relatively large head, narrow thorax, and distended abdomen. Bilateral clubfeet are also seen 


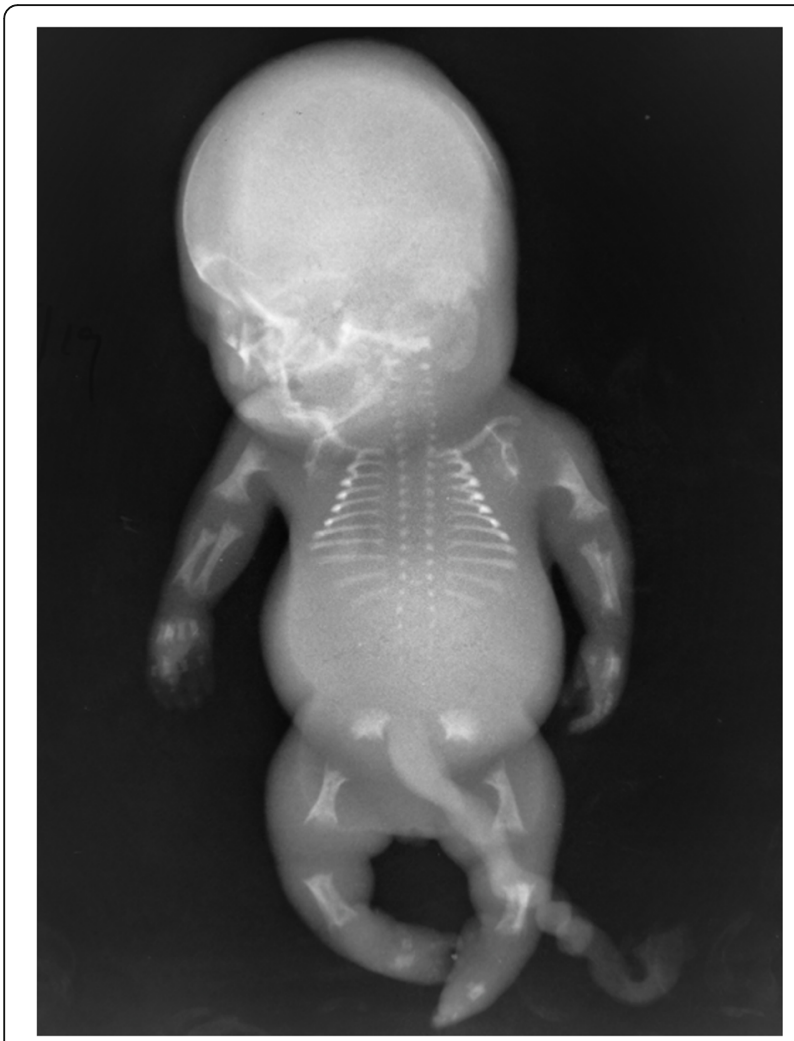

Fig. 5 Post-termination radiograph of abortus shows severely short fetal long bones, complete non-ossification of vertebral bodies (including sacrum), relative macrocrania, narrow thorax, shortening of the trunk, cupped appearance of ribs without any fractures and concavity of inferior and medial borders of the ilium. The metaphyses of long bones appeared flared with lateral spurs seen at proximal metaphyses of bilateral humeri and femora

The characteristic ultrasound and radiographic findings led to the diagnosis of achondrogenesis type II. No karyotyping or molecular analysis was done as the parents were unwilling for the same. The patient was counseled about the risk of recurrence of this condition in future pregnancy [7].

\section{Ethics approval and consent to participate}

The present study was approved by the ethical board of the hospital in which the study was performed. The parents of the fetus reported in this article had signed a written informed consent form. This case report was the reporting of a case in a medical educational center, in which all patients are informed that they may be subjects of scientific experiments and are informed of the ethical codes of conduct. This study complied with the latest version of the Helsinki Declaration.

\section{Discussion}

Achondrogenesis type II is one of the four most common lethal skeletal dysplasias with others being thanatophoric dysplasia, osteogenesis imperfecta type II, and hypophosphatasia congenita [8]. These entities share the common features of severe micromelia and pulmonary hypoplasia. However, the distinction between achondrogenesis type II and other lethal skeletal dysplasia is relatively easy as thanatophoric dysplasia shows normal bone mineralization, osteogenesis imperfecta is associated with fractures in multiple bones, and hypophosphatasia congenita shows an absence of ossification in the calvarium and the neural arches of the spine [9].

Other close differential diagnoses of this condition include hypochondrogenesis and achondrogenesis type I.

Previously, hypochondrogenesis was considered a separate entity from achondrogenesis type II. However, now it is widely accepted that these two represent a spectrum of type II collagenopathy with marked radiographic and morphologic variability [1]. Hypochondrogenesis is also a lethal dysplasia, but there is better ossification of the spine, long bones, and pelvis in this condition.

Achondrogenesis type I represents $20 \%$ of all cases of achondrogenesis [10]. It is a disorder of both endochondral as well as membranous ossification whereas type II only affects endochondral ossification [10]. Type I shares multiple features with type II in the form of partial or complete lack of ossification of the spine as well as severe limb shortening. However, the degree of demineralization is more in type $\mathrm{I}$ in the skull and iliac wings. Besides, type I is associated with multiple rib fractures. Achondrogenesis type I has an autosomal recessive inheritance and carries a recurrence rate of $25 \%$ in subsequent pregnancies.

There have been three cases of achondrogenesis type II reported from India to date [11-13]. This case represents the 4th case of this rare entity from India which is probably under-reported and under-diagnosed in our country.

We accept the drawback of our study in form of a lack of genetic or histological analysis. However, this could not be done as we could not obtain consent from the parents for the same. We feel that the constellation of imaging findings in our case is sufficient to make a diagnosis of achondrogenesis type II with a high degree of confidence. We have considered and excluded all possible differential diagnoses as the imaging findings so strikingly favor this particular entity.

\section{Conclusion}

This case highlights the classical imaging features of a rare skeletal dysplasia. The lack of mineralization of vertebral bodies is the most striking finding of this entity and warrants a search for other features. The parents need to be counseled about the lethal nature of this dysplasia and the risk of recurrence, albeit low, in future pregnancies. 


\section{Abbreviations}

FL: Femoral length; AC: Abdominal circumference

\section{Acknowledgements}

$\mathrm{Nil}$

\section{Authors' contributions}

SM conceptualized the design of this case report. SM and DI contributed to the acquisition and analysis of patient data and images. UR and SC contributed to the drafting and revision of the case report. VA contributed to the interpretation of images. All authors have agreed both to be personally accountable for their own contributions, and they have ensured that questions related to the accuracy or integrity of any part of this work, even ones in which they were not personally involved, were appropriately investigated and resolved, and the resolution was documented in the literature. All authors have read and approved the manuscript.

\section{Funding}

No one was paid during this study. The study did not have a source of funding. This study was not supported by a grant.

\section{Availability of data and materials}

All data is available based on a reasonable request.

\section{Declarations}

Ethics approval and consent to participate

The present study was approved by the ethical board of the hospital in which the study was performed. The parents of the fetus reported in this article had signed a written informed consent form. This case report was the reporting of a case in a medical educational center, in which all patients are informed that they may be subjects of scientific experiments and are informed of the ethical codes of conducts. This study was in compliance to the latest version of the Helsinki Declaration.

\section{Consent for publication}

The parents had written and signed an informed consent note that the findings may be published without any personal detail.

\section{Competing interests}

The authors declare that they have no competing interests.

Received: 29 December 2020 Accepted: 29 March 2021

Published online: 22 April 2021

\section{References}

1. Lachman R (2007) Taybi H. Taybi and Lachman's radiology of syndromes, metabolic disorders, and skeletal dysplasias

2. Saldino RM (1971) Lethal short-limbed dwarfism: achondrogenesis and thanatophoric dwarfism. Am J Roentgenol 112(1):185-197. https://doi.org/1 0.2214/ajr.112.1.185

3. Faivre L, Merrer ML, Douvier S, Laurent N, Thauvin-Robinet C, Rousseau T, Vereecke I, Sagot P, Delezoide AL, Coucke P (2004) Recurrence of achondrogenesis type II within the same family: evidence for germline mosaicism. Am J Med Genet A 126(3):308-312

4. Comstock JM, Putnam AR, Sangle N, Lowichik A, Rose NC, Opitz JM (2010) Recurrence of achondrogenesis type 2 in sibs: additional evidence for germline mosaicism. Am J Med Genet A 152(7):1822-1824

5. Krakow D, Lachman RS, Rimoin DL (2009) Guidelines for the prenatal diagnosis of fetal skeletal dysplasias. Genet Med 11(2):127-133. https://doi. org/10.1097/GIM.0b013e3181971ccb

6. Wang W, Wu Q, Sun L, Zhong X, Xu Y, Xie X, Su Z (2019) Diagnosis of prenatal-onset achondrogenesis type II by a multidisciplinary assessment: a retrospective study of 2 cases. Case Rep Obstet Gynecol 2019(4):79817677981767. https://doi.org/10.1155/2019/7981767

7. Jobling R, D'Souza R, Baker N, Lara-Corrales I, Mendoza-Londono R, Dupuis L, Savarirayan R, Ala-Kokko L, Kannu P (2014) The collagenopathies: review of clinical phenotypes and molecular correlations. Curr Rheumatol Rep 16(1):394. https://doi.org/10.1007/s11926-013-0394-3

8. Krakow D, Alanay Y, Rimoin LP, Lin V, Wilcox WR, Lachman RS, Rimoin DL (2008) Evaluation of prenatal-onset osteochondrodysplasias by ultrasonography: a retrospective and prospective analysis. Am J Med Genet A 146(15):1917-1924

9. Rumack CM, Levine D (2017) Diagnostic ultrasound E-book. Elsevier Health Sciences

10. Tongsong T, Srisomboon J, Sudasna J (1995) Prenatal diagnosis of LangerSaldino achondrogenesis. J Clin Ultrasound 23(1):56-58. https://doi.org/10.1 002/jcu.1870230112

11. Reddeppa T, Kishor H, Singhal V, Divekar D (1993) Achondrogenesis type ॥ (Langer-Saldino). Indian Pediatr 30:239-239

12. Puri RD, Thakur S, Verma IC (2007) Spectrum of severe skeletal dysplasias in North India. Indian J Pediatr 74(11):995-1002. https://doi.org/10.1007/s12 098-007-0183-y

13. Kodandapani S, Ramkumar V (2009) Antenatal diagnosis of achondrogenesis type II. JNMA J Nepal Med Assoc 48(174):155-157. https://doi.org/10.31729/ jnma.234

\section{Publisher's Note}

Springer Nature remains neutral with regard to jurisdictional claims in published maps and institutional affiliations.

\section{Submit your manuscript to a SpringerOpen ${ }^{\circ}$ journal and benefit from:}

- Convenient online submission

- Rigorous peer review

- Open access: articles freely available online

- High visibility within the field

- Retaining the copyright to your article

Submit your next manuscript at $\boldsymbol{\nabla}$ springeropen.com 